\title{
Faults Plane Orientation Deduced from the High Dense Network of Short Duration Data with Relocation of Hypocenters: Koyna-Warna Region, Western India
}

\author{
Suman Kilaru', Sanjai Kumar', Madhan Mohan Dixit ${ }^{2}$ \\ ${ }^{1}$ Ammapalem, Konijerla, Khammam, Telangana, India \\ ${ }^{2}$ National Geophysical Research Institute (NGRI), Hyderabad, India \\ Email: suman.geophy@gmail.com
}

How to cite this paper: Kilaru, S., Kumar, S. and Dixit, M.M. (2019) Faults Plane Orientation Deduced from the High Dense Network of Short Duration Data with Relocation of Hypocenters: Koyna-Warna Region, Western India. Open Journal of Earthquake Research, 8, 191-200.

https://doi.org/10.4236/ojer.2019.83011

Received: October 23, 2018

Accepted: July 8, 2019

Published: July 11, 2019

Copyright $\odot 2019$ by author(s) and Scientific Research Publishing Inc. This work is licensed under the Creative Commons Attribution International License (CC BY 4.0).

http://creativecommons.org/licenses/by/4.0/

\begin{abstract}
Identification of precise hypocenter location is useful in order to improve the faults plane orientation and seismic zone analysis. In the study area, relocated hypocenter of earthquakes in Koyna-Warna region (KWR) from the short period recorded data from 6th January 2010 to 28th May 2010 by using Cross-Correlation waveform results in Double Difference Hypocenter method [1]. The results show the significant improvement in hypocenter location and orientation in earthquake hypocenters, which is correlated with local faults plane orientation in study region. From the observations the earthquake hypocenters are lying in the depth between 3 to $8 \mathrm{~km}$. The result which identified three faults plane orientation in NNW-SSE direction and also identified new fractures in NE-SW directions between the faults plane orientation with short duration data sets the first time in India.
\end{abstract}

\section{Keywords}

Koyna-Warna Region, Cross-Correlation, Relocation Hypocenter, Fracture Zones

\section{Introduction}

The Koyna-Warna region continues to be the most significant site of an artificial water reservoir triggered seismicity, since the impounding of the Koyna reservoir 54 years ago and the nearby Warna reservoir 27 years ago [2] [3] [4]. The KWR well knows artificial reservoir earthquake region in the world, constructed on Deccan traps. Till date more than 100,000 earthquakes are recorded in which 
22 earthquakes were with magnitude $(M) \geq 5$, and have occurred within the small an area $30 \times 20 \mathrm{sq} \cdot \mathrm{km}$ of KWR.

The largest reservoir triggered earthquake of magnitude of M 6.3 occurred near the Koyna on 10 December 1967. Data for most of the previous studies [4]-[12] were recorded by a limited but widely distributed array of seismographs. Consequently, the earthquake locations and their source parameters were poorly constrained.

This study improved the precise hypocenter locations of the KWR, with covering high dens seismic network of 97 stations (Figure 1) data by using the double difference hypocenter location method [1]. The cross-correlation of seismogram ( $\mathrm{P}$ and $\mathrm{S}$ ) data is used for the relative arrival time pairs. The improved hypocenter locations allow constraining the geometry of the faults plane orientation in the study province.

\section{Data and Method}

In an attempt to improve hypocenter locations and identify the faults plane orientation in the KWR, deployed 97 portable seismographs for five months (from 6th January 2010 to 28th May 2010). The seismograph paired with the three component receiver, relatively high frequency $(4.5 \mathrm{~Hz})$ sensors and data recorded continuously at 100 samples/second. And also connected high accurate GPS sensor with a horizontal accuracy of about 5 to 10 meters. Geophone critically damped ratio at 0.707 , has a sensitivity of $32 \mathrm{v} / \mathrm{m} / \mathrm{s}$. The relatively high-frequency sensors allow for higher frequency data and more accurate first-arrival travel time picks.

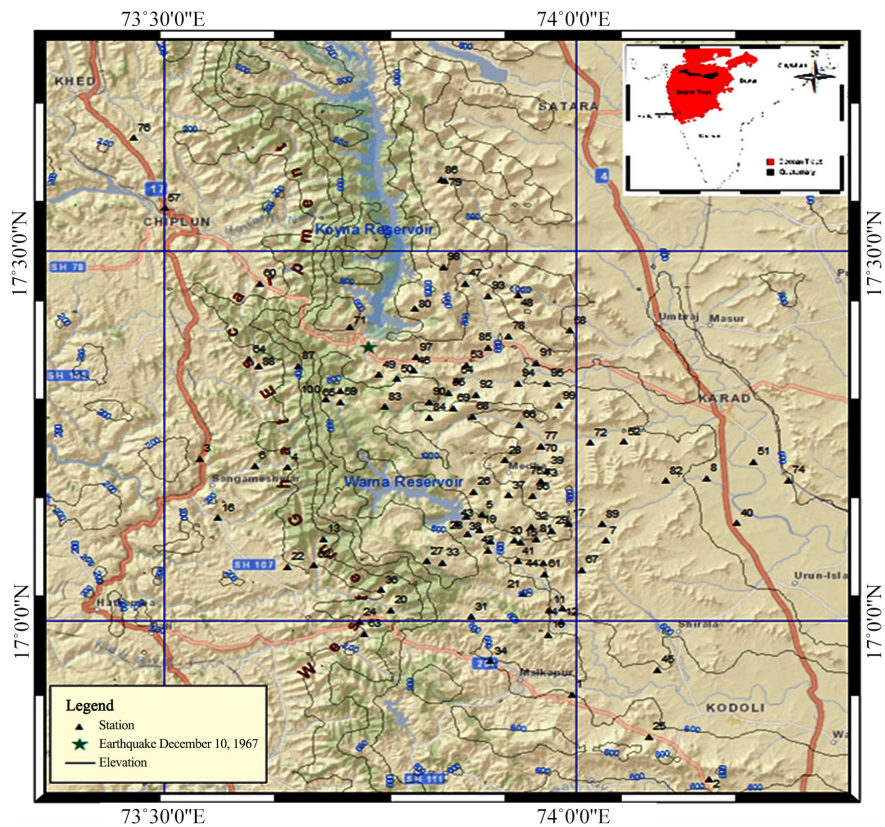

Figure 1. Study area map with regional topography with elevation contours. Temporary seismograph locations show in triangle and epicenter of the 10th December 1967 earthquake. 


\section{Initial Hypocenter Location}

The Initial hypocenters are located with the HYPO71 [13] in SEISAN software [14] with a reference one-dimensional crustal velocity model ([15], Figure 2). The HYPO71calculate the hypocenters, magnitude and first motion pattern of the earthquakes, trying to improve the hypocenter and origin time by iteratively minimizing the least square error of travel time.

\section{Cross-Correlation}

The cross-correlation function measure the similarity of two waveforms as a function of the time lag of one relative to the other waveforms, the similar waveforms can be observed at one station recorded different events when hypocenters are close (Figure 3 ). The cross correlation of two waveforms delay time lag $w(t)$ is:

$$
w(t)=u(t) * v(t)=\int_{\infty}^{\infty} u *(T) v(T+t) d t
$$

$u$ and $v$ are continuous functions of two time series, $T=$ is the time shift.

The cross correlation is achieved accurate phase arrival by correlating the similar seismograms, it is minimized the uncertainty in hypocenter locations [14].

This study utilised program CORR in SEISAN [14]; this gives the maximum correlation of similar waveforms and relative arrival times. In CORR program initial takes one waveform as a master event and cross correlation with the other events of a selected phase window with the master event.

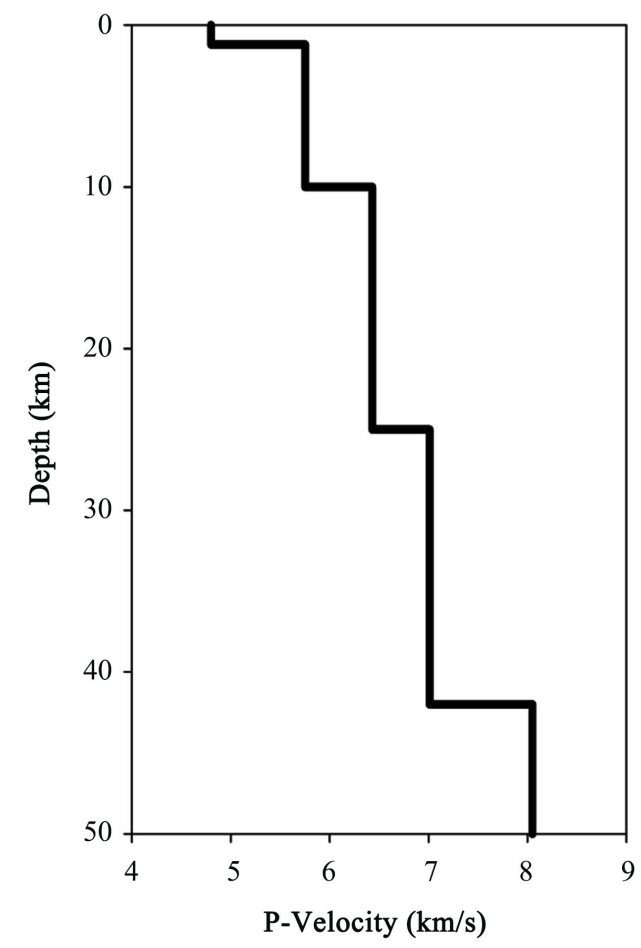

Figure 2. One Dimension velocity model (adopted from [15]). 


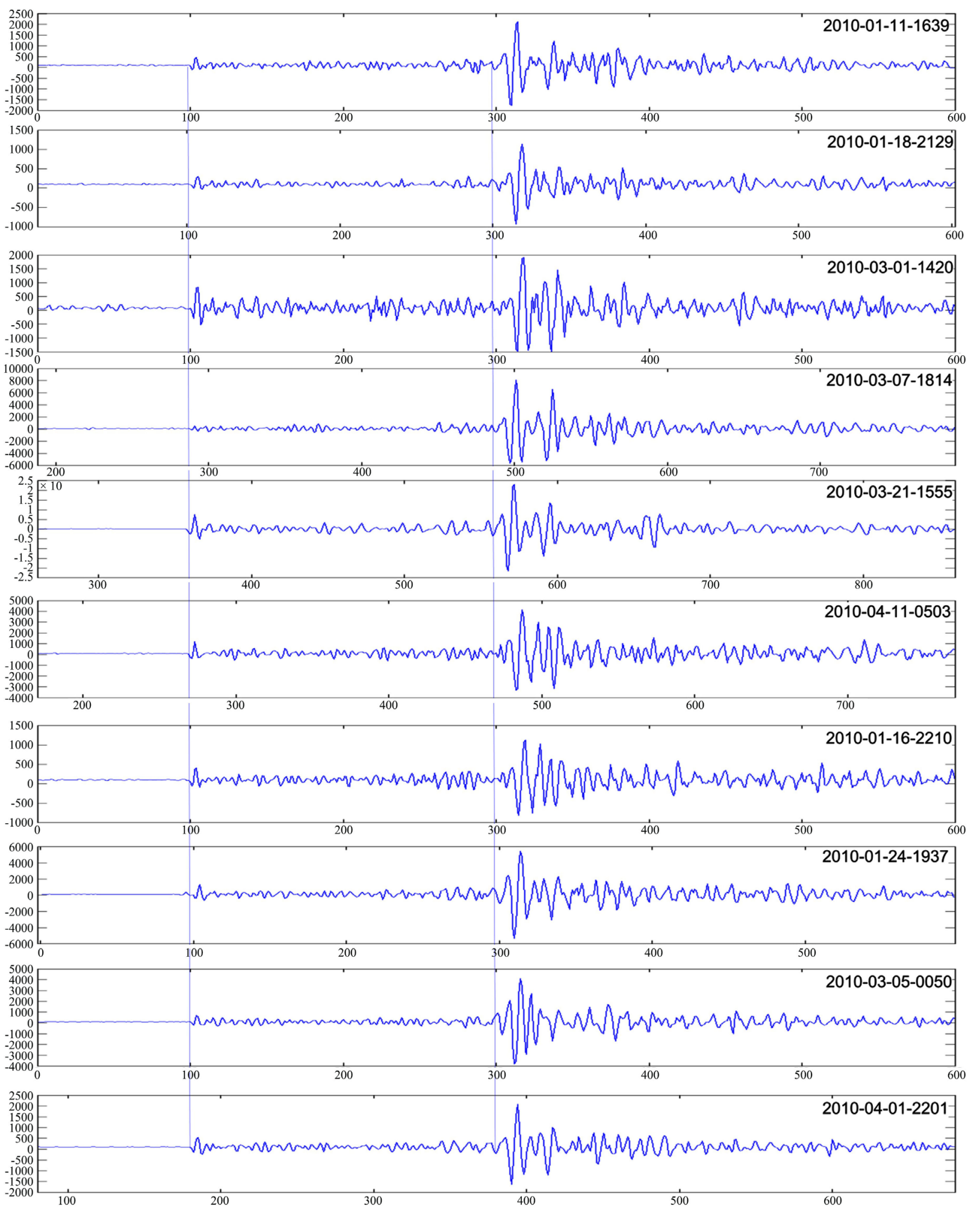

Figure 3. Cross-correlation of waveforms different earthquakes recorded at Station 68.

Computed the cross-correlation for $\mathrm{P}$ and $\mathrm{S}$ face duration of window given 6 Sec filters are applied 3 to $40 \mathrm{~Hz}$. Minimum correlation of the waveform is 0.5 $\mathrm{Sec}$, minimum correlation stations 4 and the correlation between the computed 
two events maximum distance $5 \mathrm{~km}$. Cross correlation of some events recorded at station 68 as shown in Figure 4. The output file dt.cc can be used with the double difference location program HYPODD.

\section{Double Difference Hypocenter}

To improve the accuracy of absolute earthquake location, we used the doubledifference hypocenter algorithm [1]. HypoDD relocate the event through an iterative least-squares approach that reduces the differential travel time residual between pairs of events recorded at a common station. The double-difference equation:

$$
d r_{k}^{i j}=\left(t_{k}^{i}-t_{k}^{j}\right)^{o b s}-\left(t_{k}^{i}-t_{k}^{j}\right)^{c a l}
$$

$d r_{k}^{i j}$ is the residual between observed and calculated differential travel times for the two events $i$ and $j$, recorded at station $k$. HypoDD minimizes residual double-differences of pairs of earthquakes by adjusting the vector differences between their hypocenters, and determines the interevent distances between correlated events, without need for station corrections [1] [16].

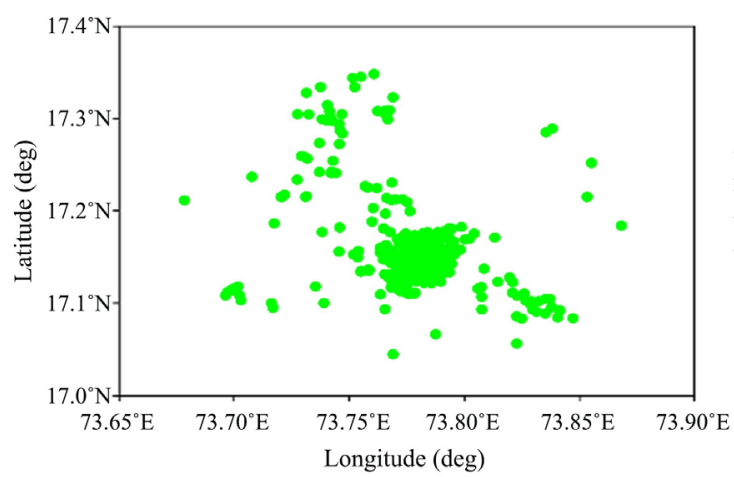

(a)

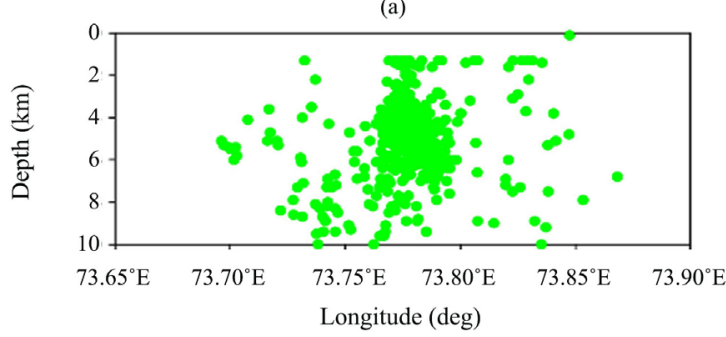

(c)

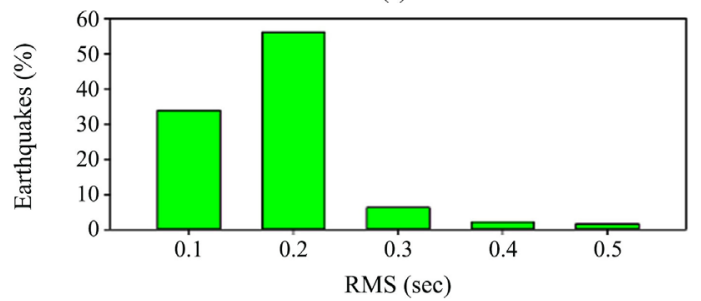

(d)

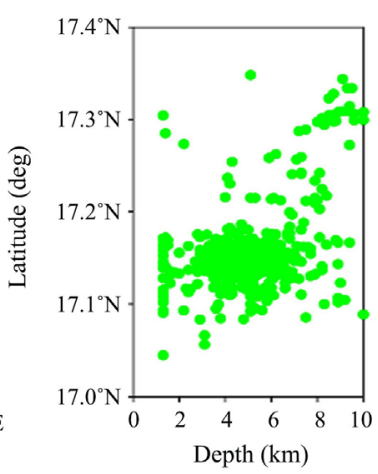

(b)

Figure 4. Epicenter location map and statics using HYPO71 in SEISAN software. (a) Seismicity location and epicenters are shown in circles; (b) Latitude vs Depth; (c) Longitude vs Depth and (d) RMS error in histogram. 


\section{Results}

The HYPO71 located 499 earthquakes show a high-density cluster of earthquakes near Warna Reservoir (Figure 4(a)).

There is an apparent deepening of hypocenters from south to north (Figure 4(b)) and several near-vertical alignments of hypocenters from west to east (Figure $4(\mathrm{c})$ ). More than $90 \%$ of the earthquakes located with the HYPO71 algorithm have RMS values between 0.5 to 0.1 (Figure $4(\mathrm{~d})$ ). On that basis, we estimate errors in hypocenter depths $0.7 \mathrm{~km}$. However, our preference in this study was to reduce the RMS values and obtain greater accuracy in the locations.

The events are cross correlated (example: station 68 recorded different events similar waveform as shown in Figure 3 ) and used in hypoDD for relocation. Out of 499 events 379 events include the P-wave cross-correlation dtimes 6227 and S-wave cross-correlation dtimes 6327 total dtimes 12,549. Figure 5(a) shows the relocation of events map after the relocation, there is an apparent gently deepening of hypocenters from south to north (Figure 5(b)) and several near-vertical alignments of hypocenters from west to east (Figure 5(c)) and error in depth

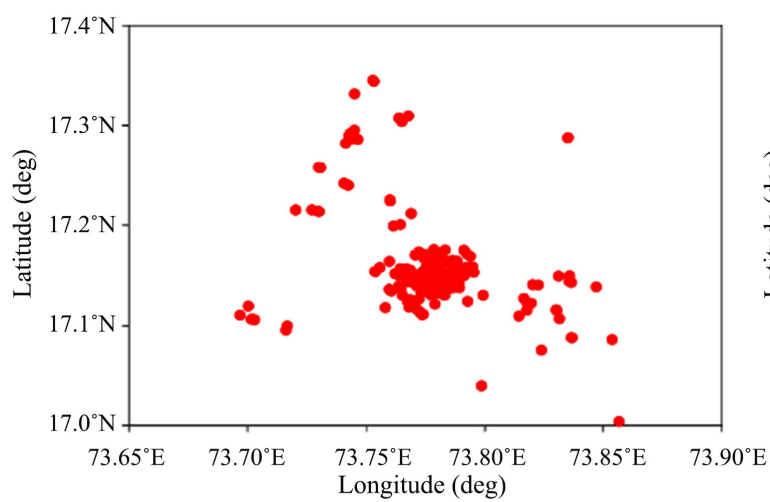

(a)

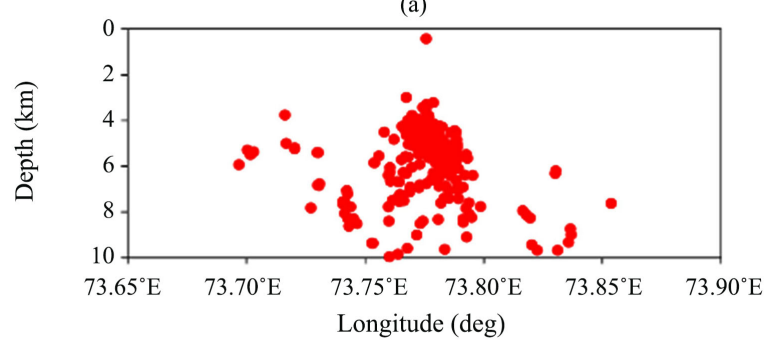

(c)

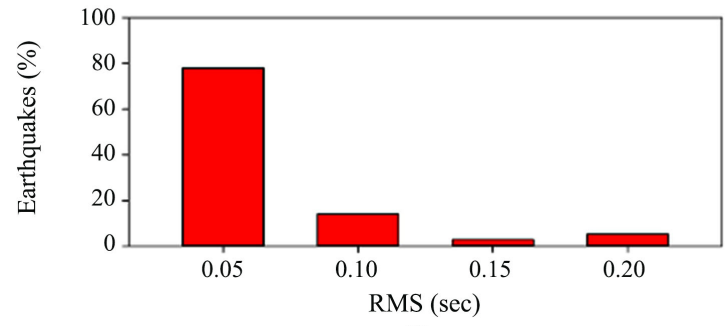

(d)

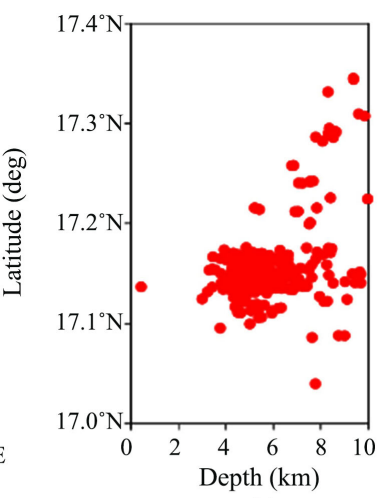

(b)

Figure 5. Epicenter location map and statics using hypoDD. (a) Seismicity location and epicenters are shown in circles; (b) Latitude vs. Depth; (c) Longitude vs. Depth and (d) RMS error in histogram. 
reduced to $0.1 \mathrm{~km}$ and RMS error reduced to 0.2 to 0.05 (Figure 5(d)). From the relocation gently observed event are compacted and these earthquakes are falling in the depth range from $3 \mathrm{~km}$ to $8 \mathrm{~km}$.

From the relocation events patterns show that the three faults in NNW-SSE direction (Figure 6). The faults (F1 - F3) are confined from the early study [17] [18]. In Figure (Figure 7(a) and Figure 7(b)) which shows closer observation changes before and after relocation with hypoDD. In Figure 7(a) in observation three faults are shows with scattered and after relocation (Figure $7(b)$ ) the events hypocenters are compacted and shows direction of faults (F1 - F3). In Figure 6 we can observe some feature between the F2 and F3 which may be formed due to F2 and F3 energy releasing and making new features in between the F2 and F3 marked with blue lines and circle (Figure 7(b)).

\section{Discussion}

The recloation of earthquakes in the study province, improved spatial distrubtion of earthquakes as well as hypocenter locations are obtained from the cross

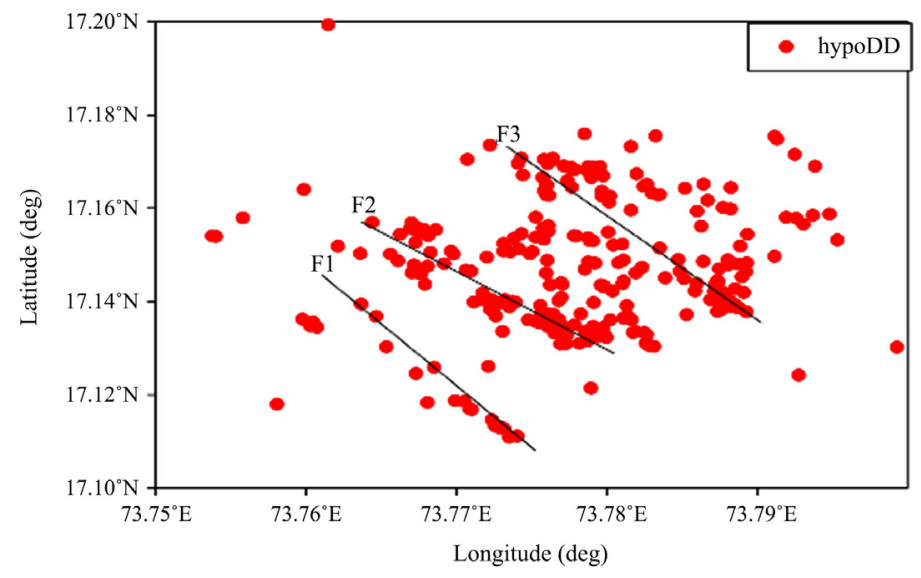

Figure 6. Relocation hypocenter with hypoDD and Faults (F1 - F3).

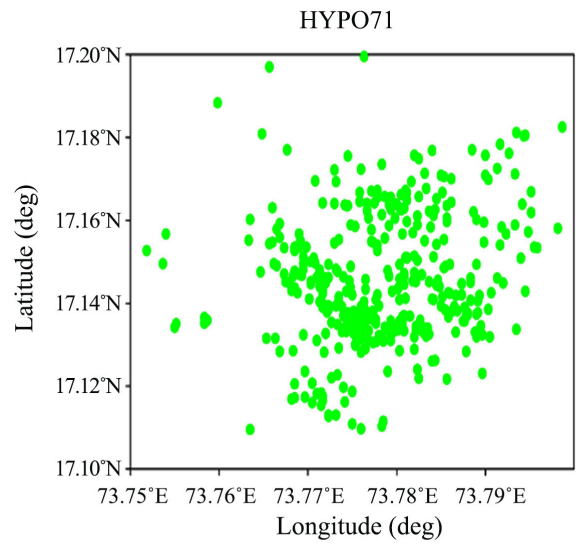

(a)

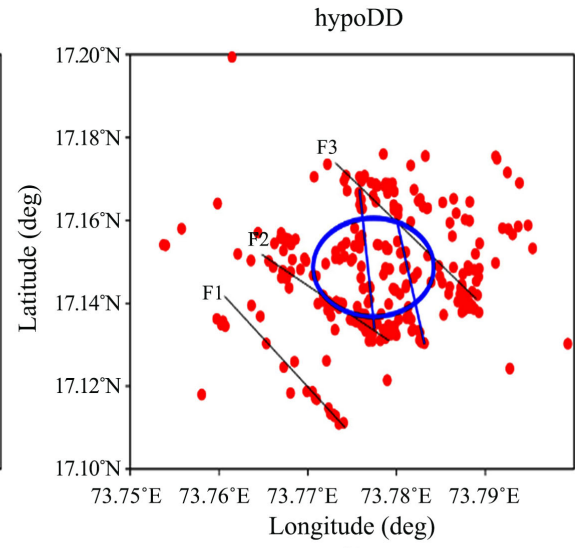

(b)

Figure 7. Comparison between before and after relocation hypocenters, (a) The hypocenters are scatter; (b) Hypocenters are compacted and shown faults and some doubted faults which shows in blue lines and circle. 
correlation of wave form data, by using double difference hypocenter method. The relocation of earthquakes are observed in the southwest of Warna reservoir, the seismicity shifting observed from the Koyna reservoir to southwest of Warna reservoir [4] with the limited network. The present obtains results shown three faults within the study area, along the lineaments [19] extending to the southeast direction, the observed faults plane orientation alinement of epicenter determination study [17] [18]. These faults plane orientation observed the high $\mathrm{p}$ wave velocity and low $S$ wave velocity and high passion ration observed, due to the saturation of rocks by high pore pressure [17]. The high pore pressure in these active fault zones may form the new faults in the study area, the observed epicenter lineation in the northeast to southwest direction (Figure 6) is concluding within the fault zone forming the new faults in northeast to southwest direction.

\section{Conclusions}

The seismicity pattern in Koyna-Warna region is concluded from the relocation of hypocenter by using hypoDD, which shows significant seismicity shift observed from Koyna reservoir to northwest of Warna reservoir.

The seismicity depth is between $3 \mathrm{~km}$ to $8 \mathrm{~km}$ and RMS error reduced from $0.2 \mathrm{sec}$ to $0.05 \mathrm{sec}$ and depth reduced $0.7 \mathrm{~km}$ to $0.1 \mathrm{~km}$.

The relocation events distribution shows the three faults in NNW-SSE direction. Between F2 and F3 it shows new faults orientation of epicenter lineation in the study area which forms due to the high pore pressure within the F2 and F3.

\section{Acknowledgements}

We thank to NGRI for supporting and publishing this work. We also thank to Mr. Sai Vijay Kumar for his technical support.

We are thankful to Reviewers for reviewing the manuscript and providing helpful suggestions.

\section{Conflicts of Interest}

The authors declare no conflicts of interest regarding the publication of this paper.

\section{References}

[1] Waldhauser, F. and Ellsworth, W.L. (2000) A Double-Difference Earthquake Location Algorithm: Method and Application to the Northern Hayward Fault, California. Seismological Society of America, 90, 1353-1368. https://doi.org/10.1785/0120000006

[2] Gupta, H.K. (2002) A Review of Recent Studies of Triggered Earthquakes by Artificial Water Reservoirs with Special Emphasis on Earthquakes in Koyna, India. Earth-Science Reviews, 58, 279-310. https://doi.org/10.1016/S0012-8252(02)00063-6

[3] Gupta, H.K. (1992) Reservoir-Induced Earthquakes. 364 p. Elsevier Publishers, Amsterdam, Netherlands.

[4] Talwani, P. (1997) Seismotectonics of the Koyna-Warna Area, India. Pure and Ap- 
plied Geophysics, 150, 511-550. https://doi.org/10.1007/s000240050091

[5] Gupta, H.K., Narian, H., Rastogi, B.K. and Mohan, I. (1969) A Study of the Koyna Earthquake of December 10, 1967. Bulletin of the Seismological Society of America, 59, 1149-1162.

[6] Rajendran, K., Harish, C.M. and Kumaraswamy, S.V. (1996) Re-Evaluation of Earthquake Data from Koyna-Warna Region: Phase I, Report to the Department of Science and Technology, 94.

[7] Chadha, R.K., Gupta, H.K., Kumpel, H.J., Mandal, P., Rao, A.N., Kumar, N., Radhakrishna, I., Rastogi, B.K., Raju, I.P., Sarma, C.S.P., Satyamurthy, C. and Satyanarayana, H.V.S. (1997) Delineation of Active Faults, Nucleation Process and Pore Pressure Measurements at Koyna (India). In: Talebi, S., Ed., Seismicity Associated with Mines, Reservoirs and Fluid Injections, Pageoph Topical Volumes, Birkhäuser, Basel, 551-562. https://doi.org/10.1007/978-3-0348-8814-1_11

[8] Mandal, P., Rastogi, B.K. and Sarma, C.S.P. (1998) Source Parameters of Koyna Earthquakes. Bulletin of the Seismological Society of America, 88, 833-842.

[9] Rastogi, B.K., Chadha, R.K., Sarma, C.S.P., Mandal, P., Satyanarayana, H.V.S., Raju, I.P., Kumar, N., Satyamurthy, C. and Rao, A.N. (1997) Seismicity at Warna Reservoir (Near Koyna) through 1995. Bulletin of the Seismological Society of America, 87, 1484-1494.

[10] Rai, S.S., Singh, S.K., Rajagopal Sarma, P.V.S.S., Srinagesh, D., Reddy, K.N.S., Prakasam, K.S. and Satyanarayana, Y. (1999) What Triggers Koyna Region Earthquakes? Preliminary Results from Seismic Tomography Digital Array. Proceedings of the Indian Academy of Sciences-Earth and Planetary Sciences, 108, 1-14.

[11] Srinagesh, D. and Rajagopala Sharma, P. (2005) High Precision Earthquake Locations in Koyna-Warna Seismic Zone Reveal Depths Variation in Brittle-Ductile Transition Zone. Geophysical Research Letters, 32, 1-4. https://doi.org/10.1029/2004GL022073

[12] Shashidhar, D., Rao, N.P. and Gupta, H.K. (2011) Waveform Inversion of Broad-Band Data of Local Earthquakes in the Koyna-Warna Region, Western India. Geophysical Journal International, 185, 292-304. https://doi.org/10.1111/j.1365-246X.2011.04935.x

[13] Lee, W.H.K. and Lahr, J.C. (1972) HYP071: A Computer Program for Determining Hypocenter, Magnitude, and First Motion Pattern of Local Earthquakes. U.S. Geological Survey, Open-File Report No. 75-311. https://doi.org/10.3133/ofr72224

[14] Ottemöller, L., Voss, P. and Havskov, J. (2011) SEISAN Earthquake Analysis Software for Windows, Solaris, Linux and Macosx. Version 9.0. https://www.uib.no/rg/geodyn/artikler/2010/02/software

[15] Kilaru, S., Kumar, S., Dixit, M.M. and Rao, P.R. (2015) 1-D Velocity Model Delineated Using Dense Seismic Network in the Koyna-Warna Region, Maharashtra, India. Journal of Indian Geophysical Union, 19, 182-189.

[16] Waldhauser, F. (2001) hypoDD: A Computer Program to Compute Double-Difference Hypocenter Locations. U.S. Geological Survey, Open-File Report No. 01-113. https://doi.org/10.3133/ofr01113

[17] Dixit, M.M., Kumar, S., Catchings, R.D., Suman, K., Sarkar, D. and Sen, M.K. (2014) Seismicity, Faulting, and Structure of the Koyna-Warna Seismic Region, Western India, from Local Earthquake Tomography and Hypocenter Locations. Journal of Geophysical Research: Solid Earth, 119, 6372-6398. https://doi.org/10.1002/2014jb010950

[18] Catchings, R.D., Dixit, M.M., Goldman, M.R. and Kumar, S. (2015) Structure of the 
Koyna-Warna Seismic Zone, Maharashtra, India: A Possible Model for Large Induced Earthquakes Elsewhere. Journal of Geophysical Research: Solid Earth, 120, 3479-3506. https://doi.org/10.1002/2014JB011695

[19] Dura-Gomez, I. and Talwani, P. (2010) Hydromechanics of the Koyna-Warna Region, India. Pure and Applied Geophysics, 167, 183-213.

https://doi.org/10.1007/s00024-009-0012-5 